\title{
CORTISOL HORMONE VARIATIONS DUE TO SOUND STRESS: PLEASANT AND UNPLEASANT SOUND
}

\section{Endocrinology}

Nisha Velayudhan*

PhD Student \& The Institute of Science, 15 Madam Cama Road, Fort, Mumbai 400032. *Corresponding Author

\section{ABSTRACT}

The current study concentrates on the severity of noise pollution on public health. During this study cortisol hormone analysis was done for confirmation of stress in animals when exposed to high decibel noise like traffic noise and temple bell clapping. During this experiment, the twoTest sets of animals (T1) set exposed to traffic noise and (T2) set to temple bell clapping were used and a standard set of animal (C) who were not exposed to any loud noise but kept in the silent zone (below $55 \mathrm{~dB}$ ). During the experiment, it became evident that loud noise did cause a surge of cortisol in the animal in the T1 group but no cortisol was present in the T2 group as well as in the Control group of animals. The presence of cortisol in an animal exposed to traffic noise implies stress in those animals and the absence of cortisol in the T2 group indicates the animals were not stressed even though they were exposed at high decibels noise. Also, the control group display absence of cortisol hormone in their blood. This concludes that sound stress is a result of exposure to pleasant or unpleasant sound irrespective of high decibel sound. This could be the reason why loud music is liked by people without causing any harm but is noise for others. It is a sheer matter of perspective of the individual which cause him/her to be stressed of loud noise.

\section{KEYWORDS}

Cortisol, Stress, Temple bell, Noise pollution

\section{INTRODUCTION:}

Hormones play a vital role in the life of an organism. They are the messenger molecules of the body that control and co-ordinates various responses and activities of an organism. Hormones are highly specific chemical substances which attach to their target organs only.

Cortisol hormone is a stress hormone which is glucocorticoid class of hormone released from the adrenal gland which brings in glycogenesis or gluconeogenesis. The function of this hormone is to co-ordinate with the hippocampus in the brain and reduces stress, basically a negative feedback mechanism in stress situations. When an animal faces stress it immediately finds an escape from the situation for which it requires strength and navigation skills which is the preparation for "fight or flight reflex". The signal for this situation is the release of cortisol hormone. It is released through the hypothalamus-pituitaryadrenal axis. The stimulus of stress signal from the surrounding like an unpleasant noise from the non-specific auditory pathway triggers the hypothalamus to release corticotropin release hormone $(\mathrm{CRH})$ which induces the pituitary gland to release adrenocorticotropic hormone $(\mathrm{ACTH})$ which in turn induces the adrenal gland to release cortisol hormone. This cortisol hormone manages the stress within the organisms by fight or flight reflexes initiating glycogenolysis or gluconeogenesis. (Sapolsky, R.M., Romero, M., et.al).

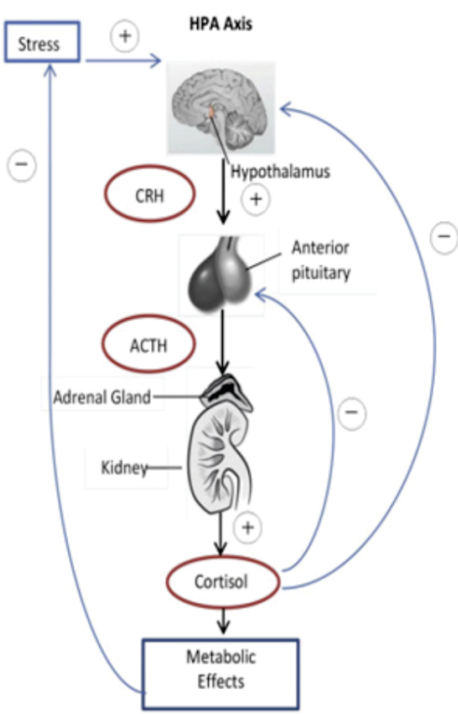

Fig. 1, Cortisol release through the HPA axis activation as a stress response (source: https://www.sciencedirect.com/)

The glucocorticoid hormone cortisol is considered a marker hormone for stress since it forms the negative feedback system for stress. (Sapolsky, R.M., Romero, M., et. al) The presence of this hormone in the blood triggers alertness in the individual and causes all the sensory system to collect maximum information from its surrounding to act on 'fight or flight' reflex against stress. (Lucassen, P.J, Pruessner, J., et.al) Cortisol is a glucocorticoid hormone. It is a steroid hormone which is released by the zona fasciculata of the adrenal cortex. This hormone has a majorrole in the physiological preparation of the organism to protect and preserve itself from crucial situations by increasing blood sugar level through gluconeogenesis which indirectly supports the increased ATP molecule formation in an organism's body (McEwen, B.S.), (Lucassen, P.J, Pruessner, J., et.al), (Sapolsky, R.M., Romero, M., et.al). The present study has a trending towards the fact that cortisol was released in blood collected from test rats exposed to high decibel traffic noise. While the control rats did not show any cortisol in their blood sample.

\section{MATERIALAND METHOD:}

MATERIAL:

Exposure chamber, Decibel metre, Blood serum sample vacutainer, white albino rats, sound i.e. speaker, HPLC machine, cortisol control, loading buffers, etc.

The animals were exposed to noise pollution in the exposure chamber specifically designed for the experiment by the researcher. The chamber was made of wood and glass. Wood was utilized because it is the best sound-absorber and glass promotes visibility of the animal during the experimentation. The exposure chamber dimensions are 3 feet*2 feet.

\section{METHODOLOGY:}

This experimentation was undertaken with 7 albino Wistar rats. They were segregated into two basic groups -test (4 no.) and control (3 no.) animals. The experiment was performed based on the experimentation consisted of two test group-Test 1 group of animals exposed to traffic noise, Test 2 animals exposed to temple bell clapping and control groups of animals. The control group of animals exposed to no loud noise but were kept in the silent zone with sound below 55 decibels. The hormone analysis of the control and experimental animals were performed by the HPLC instrument.

The sample collection i.e. blood was collected from the retro-orbital sinus near the eyes of the animal by insertion of the capillaries through the sides of the eyes and collected in vacutainer. The collection of a blood sample for all animals were done on the same i.e. the last day of exposure at the same time .i.e. 4:30 PM (Indian Time). This was done to keep in-check on the cortisol state of the animal since it is released in the normal condition through the active state .i.e. awake state of the 
animal and since the animal under consideration here are rats who are nocturnal they cannot have cortisol during this hour.

The total duration of the experiment was for 20 days. Out of the 20 days, the Test 1 animals ( 4 no.) were exposed to traffic noise for 15 days and thereafter exposed to temple bell for 5 days which became Test 2 group. The control animals ( 3 no.) were not exposed to any sound as they always kept in the silent zone with sound level below $55 \mathrm{~dB}$

The sound stressor was applied only on the test group while the control group was not exposed to high decibel sound but was kept strictly in the area below $55 \mathrm{~dB}$ sound.

The high decibel sound exposed to the test groups were between 90$110 \mathrm{~dB}$ sounds. The test animals were exposed to two sets of high decibel sound, one at a time. The first set of high decibel sound exposure was for first 15 days of experimentation Test 1 group which was a high decibel traffic noise (sound stressor) for 30 minutes daily whereas the second exposure of high decibel sound was of temple bell (therapy) for 3-5 mins daily for 5 days to the same set of stressed animals Test 2 group.

\section{RESULT:}

OBSERVATIONAND RESULTS:

\begin{tabular}{|c|c|c|}
\hline \multirow{2}{*}{ Control } & Cortisol (dL/ml) & \\
\hline \multirow{2}{*}{ Test 1 (Traffic noise) } & $\mathrm{C} 1$ & - \\
\cline { 2 - 3 } & $\mathrm{C} 2$ & - \\
\cline { 2 - 3 } & $\mathrm{T} 1$ & 155 \\
\cline { 2 - 3 } & $\mathrm{T} 1$ & 150 \\
\hline \multirow{2}{*}{ Test 2 (Temple Bell Clapping) } & $\mathrm{T} 1$ & 145 \\
\cline { 2 - 3 } & $\mathrm{T} 2$ & - \\
\cline { 2 - 3 } & $\mathrm{T} 2$ & - \\
\hline
\end{tabular}

Tab. 1, Cortisol reports

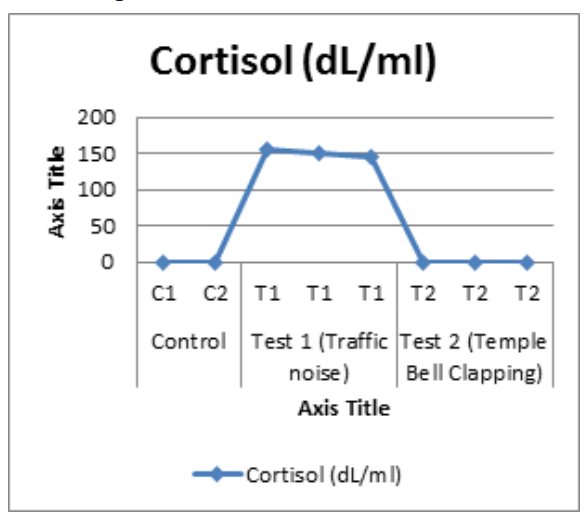

\section{Chart. 1, Representation of cortisol}

As per the observation table, it is found that the control animals and Test 2 animal's (who were exposed to temple bell clapping) blood sample did not contain cortisol, but, the Test 1 animals had cortisol hormones present in the blood sample which indicates stress in Test 1 animal.

\section{DISCUSSION:}

The present research has thrust on the levels of cortisol released due to noise stress. It was observed that cortisol levels are none in the control animals as they are not exposed to any of the traffic sounds. They also ate normal food and water regularly. But in the test group which was exposed to traffic noise, the presences of cortisol levels were observed. These observations are parallel to the finding of Phillips, L.J., McGorry, P.D., Garner, B., Thompson, K.N., Pantelis, K., Wood, S.J., Berger, G., 2006 wherein they studied the relationship between psychological stress, HPA axis functioning and the hippocampus leading to the presence of cortisol in the stressed animal. Similarly, the current studies are also in response to the findings made by Sapolsky, R.M., Romero, L.M., Munck, A.U., 2000 in which they have emphasised the secretion of glucocorticoid in response to stress. And also as seen in the work done by Sundareswaran Loganathan, Sheeladevi Rathinasamy, 2016 who has monitored the corticosterone level in response to the therapeutic plant extract Scoparia dulcis. cortisol in animals exposed to the sound of temple bell clapping at the same high decibel as traffic noise. This leads us to a very important aspect of the sound study of mindfulness. But mindfulness concentrates on low and smooth sound, not loud sound as high as 100$110 \mathrm{~dB}$ sound.

This has to be understood as the loud sound or smooth sound is analysed by the brain as pleasant and unpleasant by the brain and respond to sound in accordingly Chanda, M.L., Levitin, D.J., 2013.

\section{ACKNOWLEDGEMENT:}

I want thank my organization The Institute of Science, Fort, Mumbai and my PhD guide Dr. Varsha Andhare for allowing to do this work in the Zoology department and for their support and guidance for the accomplishment of this work.

\section{Funding:}

Since this was part of the $\mathrm{PhD}$ work it was completely self-funded by the $\mathrm{PhD}$ student Nisha Velayudhan.

\section{REFERENCE:}

. Chanda, M.L., Levitin, D.J., (2013), The Neurochemistry of Music, Trends in Cognitive Sciences, 17(4), 179-193

2. Harpreet Kour, Rajashree, R., Gougar, S.S., An experimental study to evaluate the effect of instrumental Indian classical and Western music therapy on learning and memory in stress induced young rats. IOSR Journal of Pharmacy, ISSN:2250-3013, Volume 2 Issue stress induced young rats. IOS J

3. Jamir, L., Nongkynrih, B., Gupta, S.K. (2014). Community noise pollution in urban India: Need for public health action. Indian Journal of Community Medicine, 39(1), 8 12 .

4. Khalfa, S., Dalla Bella, S., Roy, M., Peretz, I., Lupien,S.J., Effect of relaxing music on salivary cortisol level after Psychological stress. New York Academy of Science 999 (2003) pp : 374-376

5. Knight, C.R., Swaddle, J.P., (2011), How do Glucocorticoids influence stress response? Integrating permissive, suppressive, stimulatory, and preparative actions. Endocrine Review, 2(1), 55-89.

6. Knight, C.R., Swaddle, J.P., (2011). How and why environmental noise impact animals: an integrative, mechanistic review, Pubmed NCBI, 14(10) 1052-1061.

7. Lucassen, P.J, Pruessner, J., Sousa, .N., Almeida, O.F.X., Van Dam, .A.M., Rajkowska, Lucassen, P.J, Pruessner, J., Sousa, .N., Almeida, O.F.X., Van Dam, .A.M., Rajkowska,
J., • Swaab \& D.F, Czéh, B. (2014). Neuropathology of stress. Acta Neuropathol, $127,109-135$

8. McEwen, B.S. (2000).The neurobiology of stress: from serendipity to clinical relevance. Brain Research, 886, 172-189.

9. Passchier-Vermeer, W., Passchier, W.F. (2000). Noise Exposure and Public Health. Environmental health perspectives, 108(1), 123-13

10. Phillips, L.J., McGorry, P.D., Garner, B., Thompson, K.N., Pantelis, K., Wood, S.J. Berger,G., (2006). Stress, the hippocampus and the hypothalamic-pituitary-adrenal axis: implications for the development of psychotic disorders. Australian and New Zealand Journal of Psychiatry, 40, 725-741.

11. Reardon, G.E., Caldarella, A.M., Canalis, E., Determination of serum cortisol and 11Deoxycortisol by Liquid Chromatography. Clinical Chemistry, Vol. 25, No..1, 1979, pp $122-126$

12. Salamon, E., Kim, M., Beaulieu, J., Stefano, G.B., (2003), Sound therapy induced relaxation: down regulating stress processes and pathologies, Med Sci Monit, 9(5), RA116-121.

13. Sapolsky, R.M., Romero, L.M., Munck, A.U., 2000, How do glucocorticoids influence stress responses? Integrating permissive, suppressive, stimulatory, and preparative actions, The endocrine society, 21(1),55-89.

14 Spiers, J.G. Chen, HJC. Sernia, C., Lavidis, N.A. (2015). Activation of the hypothalamic-pituitary-adrenal stress axis induces cellular oxidative stress. Frontiers of Neuroscience, $8(456)$

15. Stansfeld, S.A., Berglund, B., Clark, C., Lopez-Barrio, Fischer, P., Ohrstrom, E., Haines, M.M., Head, J., Hygge, S., Kamp, I., Berry, B.F., (2005). Aircraft and road traffic noise an children's cognition and health: a cross-national study, The Lancet, Vol. 365, 1942-49.

16. Sundareswaran Loganathan, Sheeladevi Rathinasamy, 2016, Alteration in memory an Electroencephalogram waves with sub- acute noise stress in Albino rats and safeguarded by Scoparia dulci, Pharmacognosy Magazine, Vol 12(45), S7-S13.

17. Turner, J.G., Parrish, J.L., Hughes, L.F., Toth, L.A., Caspary, D.M. (2005). Hearing in Laboratory Animals: Strain Differences and Non-auditory Effects of Noise. National Institute of Health, 55(1), 12-23.

18. Uno, H., Tarara, R., Else, J.G., Suleman, M.A., Sapolsky, R.M. (1989). Hippocampal Damage Associated with Prolonged and Fatal Stress in Primates. The Journal of Neuroscience, 9(5), 1705-1711.

19. Westman, J.C., Walter, J.R., (1981). Noise and Stress: A comprehensive approach, Environmental health perspectives, Vol 41, 291-309. 